Original Research Article

\title{
Survey of use of over the counter drug and other than over the counter drugs among medical students, nursing and technician staff of a tertiary care teaching hospital
}

\author{
Priyanka D. Patel*, Kamlesh P. Patel, Supriya D. Malhotra
}

\begin{abstract}
Department of Pharmacology, Smt. NHL Municipal medical College, Ahmedabad, Gujarat, India
\end{abstract}

Received: 06 January 2017

Accepted: 06 February 2017

*Correspondence to:

Dr. Priyanka D. Patel,

Email:

drpriyankarpatel@gmail.com

Copyright: (C) the author(s), publisher and licensee Medip Academy. This is an openaccess article distributed under the terms of the Creative Commons Attribution NonCommercial License, which permits unrestricted noncommercial use, distribution, and reproduction in any medium, provided the original work is properly cited.

\begin{abstract}
Background: To find out pattern and extent of use of OTC and other than OTC drugs among medical students, nursing and technician staff.

Methods: Study began after taking permission and approval from Institutional Review Board (IRB). Medical student, nursing and technician staff of tertiary care teaching hospital was enrolled after written informed consent. Pre validated questionnaire regarding use of such use was administered to each participant.

Results: A total of 200 participants responded to questionnaire, M:F ratio was 1:1.7. Majority of the participants had taken OTC drugs for cough/cold (72.6\%) followed by headache/ body ache $(71.1 \%)$. Paracetamol $(81 \%)$ followed by Diclofenac (42.5\%), ibuprofen $(37.8 \%)$ were the most common drugs taken. About $85 \%$ participants had taken antimicrobial considering it as an OTC product. Most commonly used antimicrobials were metronidazole (19.4\%) followed by levofloxacin (17.9\%).Most common reason for self medication was the perception that the disease wasn't serious $(44.8 \%)$, favourable prior advertisement $(34.3 \%)$. About $52 \%$ requested for drug by mentioning name of drug. Most (50.7\%) felt that OTC drug improved their illness. 45.9\% stopped when symptoms disappeared. Majority of the participants $(57.2 \%)$ believed use of OTC drug is a good practice. Most of the participants $(56.7 \%)$ believed they can treat symptoms with OTC drugs.64.7\% participants believed use of OTC drug is beneficial for them. Most of the participants lack the knowledge for dose $(73.6 \%)$ and frequency $(68.2 \%)$ of drug. A substantial number of participants $(58.61 \%)$ were taking drugs outside OTC list.

Conclusions: Awareness and dangers of misuse of OTC medications among all the participants was less. Therefore it is suggested that proper education should be imparted regarding illness where self-administration of OTC drugs to be employed.
\end{abstract}

Keywords: Awareness, Misuse, Over the counter, Self-medication

\section{INTRODUCTION}

Over the counter medicine are defined as drugs that are safe and effective for use by the general public without a prescription. ${ }^{1}$ These drugs are often located on shelves in pharmacies with easy access by patients, but may also be located in non pharmacy outlets, such as grocery stores, convenience marts. ${ }^{2}$ OTC medications are effective in treating common ailments, and it help the patient to select safe, effective product. ${ }^{3}$ Developed countries reported half and two-thirds of the population used NPM (non prescription medicine), including over-the-counter medicines (OTC). ${ }^{4-6}$

Self-medication behaviour of society can be determined by the knowledge of NPM. ${ }^{7}$ Self-medication is different than over the counter drugs. Self-medication with OTC medicines is sometimes referred to as 'responsible' selfmedication to distinguish this from the practice of 
purchasing and using a prescription medicine without a doctors' prescription.

Knowledge of OTC medicines is useful for patient to manage common disease and it also decrease the cost of therapy and also decrease the time of patient. Though OTC medicine are useful so much but there are also some disadvantages like it reduces opportunities for counselling about possible lifestyle therapies (e.g. exercise and diet), there are chances of misdiagnosis and some adverse drug effect.

And because of it in spite of decrease in cost of therapy it would rather increases the cost in future and worsens patient's condition. It is very important these over-thecounter (OTC) products to be used correctly because like the other medications they may provoke serious adverse drug reactions and interactions. ${ }^{3}$ There is no regulation for use of over the counter drugs in India.

Present study was planned to provide baseline data regarding use and knowledge of over the counter drugs among medical students nursing and technician staff of a tertiary care teaching hospital. Present study was done to find out pattern and extent of use of OTC drugs and other than OTC drugs among medical students, nursing and technician staff of a tertiary care teaching hospital.

\section{METHODS}

It is a prospective cross sectional questionnaire based observational study. It was carried out at tertiary care teaching hospital over a period of 2 month. The study was conducted after obtaining the permission from the Institutional review board.

Objectives and procedure of the study were explained to the participants and those who were willing to fill the informed consent form were enrolled for the study. A pre-validated questionnaire regarding use of OTC drugs were distributed among the participants. The filled questionnaire feedbacks were retrieved from 200 participants.

All data obtained were analyzed using the Microsoft Excel software 2016. Descriptive analysis was performed by SPSS demo version 20 .

\section{RESULTS}

In our study a total of 200 participants responded to questionnaire. Among them M:F ratio was 1:1.7. Out of 200 participants 90 medical students, 60 nursing staff and 50 technician staff are there (Figure 1). Mean age of participants is 30.68 year. Out of 200 participants 61 were on treatment on regular basis (Figure 2).

Majority of the participants had taken OTC drugs for cough/cold $(72.6 \%)$ followed by headache/body ache (71.1\%) (Figure 3).

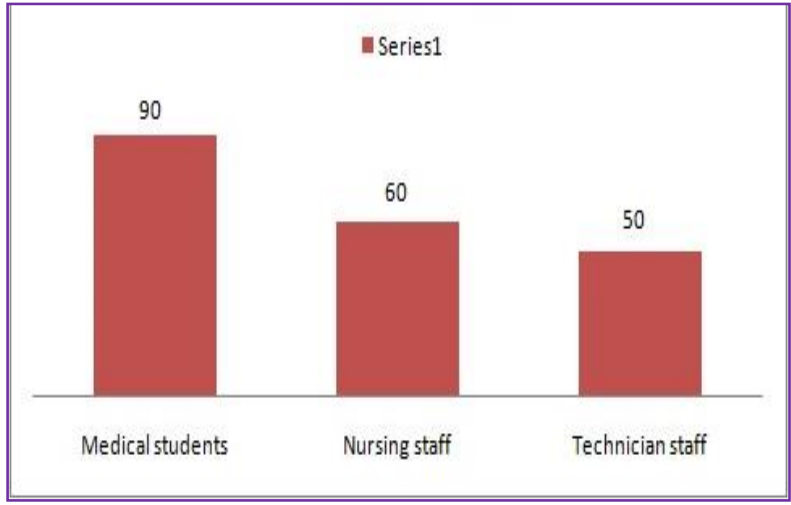

Figure 1: Total number of participants.

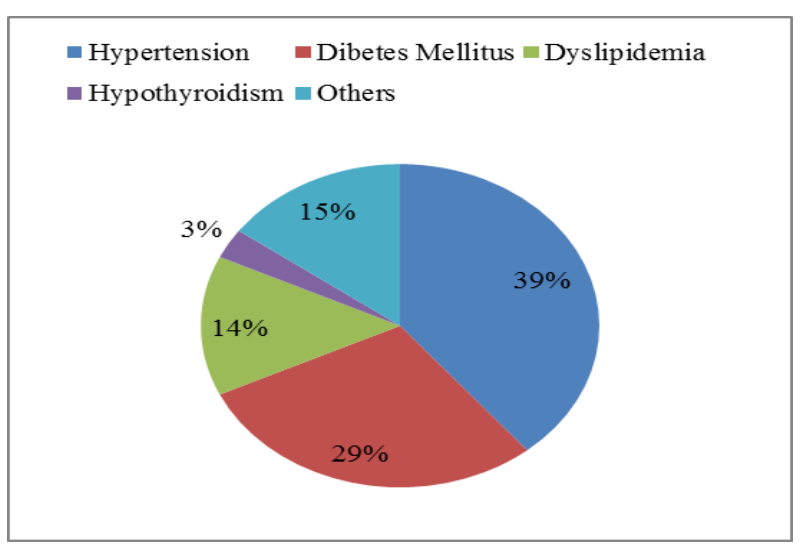

Figure 2: Morbidity pattern in participant (\%).

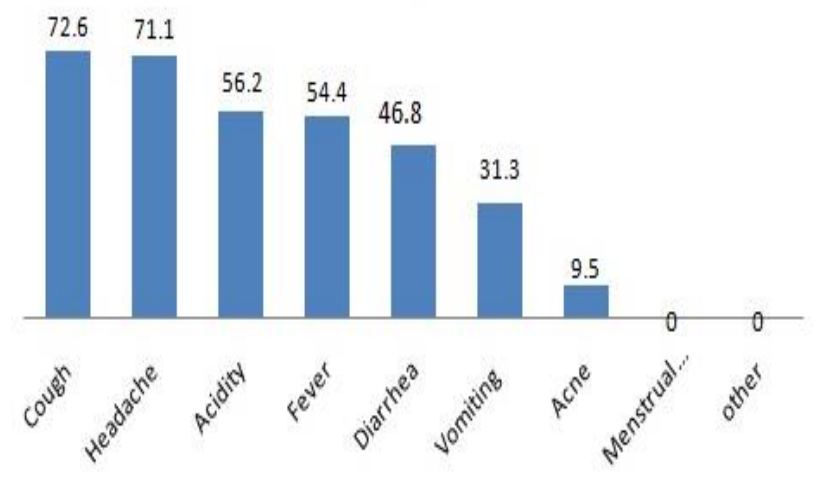

Figure 3: Common symptoms for that OTC were used by participants.

Paracetamol (82\%) followed by diclofenac sodium $(42.5 \%)$ and ibuprofen $(37.8 \%)$ were the most common drugs taken (Figure 4).

About $85 \%$ participants had taken antimicrobial considering it as an OTC product. Most commonly used antimicrobials were metronidazole $(19.4 \%)$ followed by levofloxacin (17.9\%) (Figure 5).

Most common reason found in our study for selfmedication was the perception of the participants that the 
disease wasn't serious (44.8\%), they get good opinion from family members $(42.8 \%)$ and the same number of participants believes that favourable prior experience with the same drug, and influenced by advertisement (34.3\%). About $52 \%$ requested for drug by mentioning generic name of drug name of drug. Most $(50.7 \%)$ felt that OTC drug improved their illness.

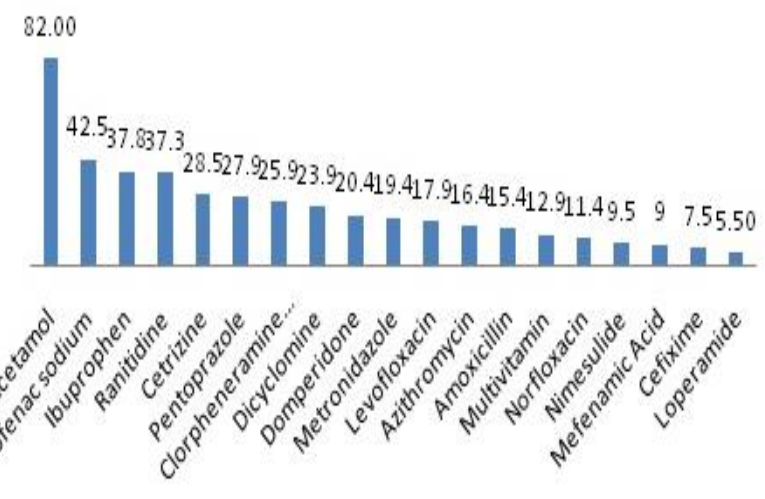

Figure 4: Total no. of drugs used (\%) by participants.

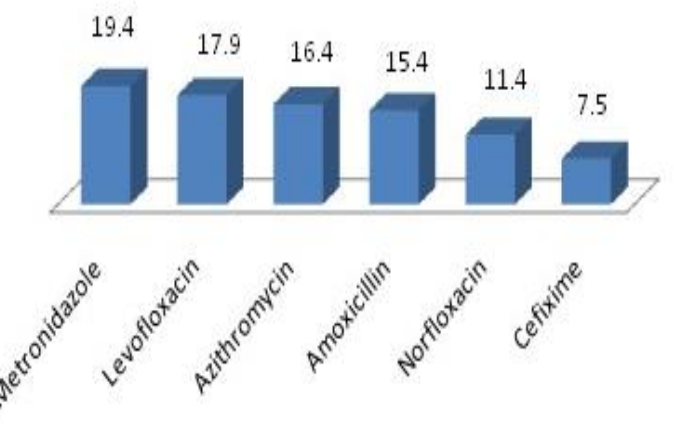

Figure 5: Total no. of antibiotics used by participants.

$45.9 \%$ stopped when symptoms disappeared. Majority of the participants $(57.2 \%)$ believed use of OTC drug is a good practice. Most of the participants $(56.7 \%)$ believed they can treat symptoms with OTC drugs. $64.7 \%$ participants believed use of OTC drug is beneficial for them. Most of the participants lack the knowledge for dose $(73.6 \%)$ and frequency $(68.2 \%)$ of drug. A substantial number of participants $(58.61 \%)$ were taking drugs outside OTC list.

\section{DISCUSSION}

This study was undertaken to get insight into the use of OTC product among paramedical staff. In our study, a total of 200 participants were enrolled. In our study number of females reported use of OTC products more in comparison to males, similar observations were made in studies from India. ${ }^{9,10}$ Gender is considered as an important factor in self-medication patterns among young adults including students. ${ }^{11}$ Out of 200 participants 90 were medical students, 60 nursing staff,50 technician staff responded to questionnaire. Level of education was found to have a significant association with the type of NPM purchased. ${ }^{7}$

Out of 200 participants none of the participant has habit of tobacco chewing, alcohol or smoking. In our study, out of 200 participants 61 were on treatment on regular basis. In our study all participants were aware of over the counter drugs and treated themselves with over the counter medicine.

Among them about 52\% requested for drug by mentioning generic name of drug. Most of the participants lack the knowledge for dose $(73.6 \%)$ and frequency $(68.2 \%)$ of drug. These findings suggest that participants have the knowledge of the drug name but the drug administration part was lacking. Irrational use of drugs may result in accidental drug poisoning. ${ }^{12}$

Majority of the participants had taken OTC drugs for cough/cold (72.6\%). Similar observations are obtained in studies from Western and Southern part of India and in Turkey, Greece, in which cough and cold was the most common symptom for self-medication. ${ }^{11,13-15}$ In present study $48.8 \%$ participants took OTC products for diarrhoea. In studies from Nigeria, diarrhoea and gastrointestinal infections were reported as the most common indication. ${ }^{16}$

In our study $54.7 \%$ participants used OTC products for fever; study in costal south India shows fever was the most common reason for self-medication ${ }^{12}$.In our study Paracetamol $(81 \%)$ was the most common drug taken. Antipyretics were the most common class of drugs selfmedicated by majority of the participants in previous study, Similar observations were made in a study from South India and Ethiopia. ${ }^{12,13,17}$ In present study Diclofenac sodium (42.5\%) followed by ibuprofen $(37.8 \%)$ were the second most common drug taken. In studies from Iran, Mozambique, and Egypt analgesics were the most common group of drugs self-medicated. ${ }^{18-}$ 20

In our study about $85 \%$ participants had taken antimicrobial considering it as an OTC product. Most commonly used antimicrobials were metronidazole $(19.4 \%)$ followed by levofloxacin $(17.9 \%)$. Beta lactams were the most common class of antibiotics frequently self-medicated in previous study. ${ }^{12,21,22}$

A major problem with self-medication with antimicrobials is the emergence of human pathogens resistance. Self-medication with antibiotics is of serious medical concern. Antimicrobials resistance is a current problem world-wide particularly in developing countries, where antibiotics are often available without a prescription. The important public health threat of antibiotic resistance depends on antibiotic overuse/misuse. ${ }^{16}$ 
Most common reason for self-medication was the perception that the disease wasn't serious (44.8\%), Similar observations are obtained in some previous studies. ${ }^{11-13}$ In a study from Tamil Nadu ${ }^{18}$ most students practiced self-medication as it was time saving, whereas in Punjab the most common reason for self-medication was for quick relief favorable prior experience $(42.8 \%)$, good opinion from family members (42.8\%) and influenced by advertisement (34.3\%). ${ }^{23}$ Previous study also shows that several aspects influence self-medication, such as education, family, advertising, legislation, having previous experience with a symptom or disease, importance attributed to a disease, and economic issues. ${ }^{24}$

Most of the participants $(56.7 \%)$ believed they can treat symptoms with OTC drugs, and $64.7 \%$ participants believed use of OTC drug is beneficial for them. These findings suggest that most of the participants are using drugs just to suppress symptoms. And (50.7\%) felt that OTC drug improved their illness and $45.9 \%$ stopped when symptoms disappeared. This observation depicts that the use of antibiotics as an OTC product can lead to misuse of antibiotics and it will be a great concern for the development of drug resistance.

A substantial number of participants (58.61\%) were taking drugs outside OTC list. This A large number of participants in our area are taking medications belonging to both OTC and non-OTC list. The percentage of self medication might be change along with locality and region.

Majority of the participants (57.2\%)believed use of OTC drug is a good practice, which is indeed a great concern to the society because participants are not aware which drugs to be taken for which indication, what is the ideal duration for the drugs, what is the dosage regimen of the drugs and when to stop the drugs. Excessive use of nonOTC drugs as OTC can lead to extra burden of cost, development of resistance and exhaustion of drug reserves.

\section{Strength of the study}

Our study was focused on knowledge, attitude and practice of OTC among medical students and nursing and technician staff.

\section{Limitation}

Single centre based study; this is a questionnaire based study. Validity of questionnaire is necessary which the original author of the questionnaire hasn't focused on. So, there may be chance of false answers.

Chances of bias can be there. Lake of proper guideline difficult to compare among OTC and other than OTC product based on National Guidelines. Small numbers of participants were enrolled in study.

\section{CONCLUSION}

We concluded that Awareness and dangers of misuse of OTC medications among all the participants was little. Therefore it is suggested that proper education should be imparted regarding illness where self-administration of OTC drugs to be employed.

\section{ACKNOWLEDGEMENTS}

Authors would like to express their gratitude to all the respondents for spending their valuable time to answer the questionnaire that helped them to successfully complete the study. Authors are also thankful to the institutional review board of Smt. NHL municipal medical college that permitted to conduct such a survey study.

\section{Funding: No funding sources}

Conflict of interest: None declared

Ethical approval: The study was approved by the Institutional Ethics Committee

\section{REFERENCES}

1. U.S. Food and Drug Administration Protecting and Promoting Your Health Drug Applications for over the counter (OTC) Drugs. Drug Applications for Over the Counter (OTC) Drugs. Available from: http://www.fda.gov/drugs/developmentapprovalproce ss/howdrugsaredevelopedandapproved/approvalappli cations/over-the-counterdrugs/default.htm

2. Over the Counter Medications. Available from: http://www.drugs.com/otc/ (OTC (Over the Counter) Drug Database Drugs.Com)

3. Corelli RL, Katzung BG, Masters SB, Trevor AJ. Therapeutic and Toxic Potential of Over-the-Counter Agents. IN. Eds Basic and Clinical Pharmacology. $12^{\text {th }}$ ed. New Delhi: Tata McGraw Hill Education Private limited; 2012:1115-1124.

4. News. Americans at risk from self-medication, survey reveals. Am J Health Syst Pharm. 1997;54:2664-6.

5. Hassali MA, Mohamad Yahaya AH, Shafie AA, Saleem F, Chua GN, Aljadhey H. Patterns and Predictors of Non-Prescription Medicine Use among Malaysian Pharmacy Patrons: A National Cross Sectional Study. 2013;8(4):e59231.

6. Bradley C, Blenkinsopp A Over the counter drugs: the future for self medication. Brit Med J. 1996;312:835-7.

7. Hassali1 MA, Mohamad Yahaya AH, Shafie AA, Saleem F, Chua GN et al. Patterns and Predictors of Non-Prescription Medicine Use among Malaysian Pharmacy Patrons: A National Cross Sectional Study. 2013;8(4):e59231.

8. Mohamed STK, Sankar C. Dilip C, Azeem AK. Self medication with over the counter drugs: A questionnaire based study, Der Pharmacia Lettre, 2011;3(1):91-8. 
9. Banerjee I, Bhadury T. Self-medication practice among undergraduate medical students in a tertiary care medical college, West Bengal J Postgrad Med. 2012;58(2):127-31.

10. Badiger S, Kundapur R, Jain A, Kumar A, Pattanshetty S. Selfmedication patterns among medical students in South India. Australas Med J. 2012;5(4):217-20.

11. Banerjee I, Bhadury T. Self-medication practice among undergraduate medical students in a tertiary care medical college, West Bengal J Postgrad Med. 2012;58(2):127-31.

12. Kanchan T, Unnikrishnan B, Rekha T, Mithra P, Kulkarni V, Papanna MK, et al. Perceptions and Practices of Self-Medication among Medical Students in Coastal South India. 2013;8(8):217-20.

13. Badiger S, Kundapur R, Jain A, Kumar A, Pattanshetty S, et al. Selfmedication patterns among medical students in South India. Australas Med. 2012;5(4):217-20.

14. Buke C, Hosgor-Limoncu M, Ermertcan S, Ciceklioglu M, Tuncel M. Irrational use of antibiotics among university students J Infect. 2005;51(2):135-9.

15. Skliros E, Merkouris P, Papazafiropoulou A, Gikas A, Matzouranis G. Self-medication with antibiotics in rural population in Greece: A cross sectional multicenter study. BMC Fam Pract. 2010;11:58.

16. Olayemi OJ, Olayinka BO, Musa AI. Evaluation of Antibiotic Self-Medication Pattern amongst Undergraduate Students of Ahmadu Bello University (Main Campus), Zaria, Research Journal of Applied Sciences Engineering and Technology. 2010;2(1):358.

17. Gutema GB, Gadisa DA, Kidanemariam ZA, Berhe DF, Berhe AH. Self-Medication Practices among Health Sciences Students: The Case of Mekelle University J Appl Pharmaceutical Sci. 2011;01(10):183-9.
18. Kayalvizhi S, Senapathi R. Evaluation of the perception, attitude and practice of self-medication among business students in 3 select cities, South India. IJEIMS. 2010;1(3):40-4. Available: http://www.ijcns.com/pdf/40-44. Accessed:2013 Feb 27

19. Lunet N, Carvalho R, Langa J, Muanantatha M. Patterns in the use of medicines by university students in Maputo, Mozambique. Cad Saude Publica. 2007;23(12):2845-52.

20. El Ezz NF, Ez-Elarab HS. Knowledge, attitude and practice of medical students towards self-medication at Ain Shams University, Egypt J Prev Med Hyg. 2011;52(4):196-200.

21. Fadare JO, Tamuno I. Antibiotic self-medication among university medical undergraduates in Northern Nigeria.J Public Health Epidemiol. 2011;3(5):217-20.

22. Donkor ES, Tetteh-Quarcoo PB, Nartey P, Agyeman IO. Self-medication practices with Antibiotics among tertiary level students in Accra, Ghana: a crosssectional study. Int J Environ Res Public Health. 2012;9(10):3519-29.

23. Gupta V, Bansal P, Manhas R, Singh Z, Ghaiye P. Preferred system of medicine and reasons of selfmedication among college students in Malwa region of Punjab. J Drug Deliv and Ther. 2011;1(2):27-9.

24. Sclafer J, Slamet LS, de Visscher G. Appropriateness of self-medication method development and testing in urban Indonesia.J Clin Pharm Ther. 1997;22(4):261-72.

Cite this article as: Patel PD, Patel KP, Malhotra SD. Survey of use of over the counter drug and other than over the counter drugs among medical students, nursing and technician staff of a tertiary care teaching hospital. Int J Basic Clin Pharmacol 2017;6:592-6. 